The ability to deal with long cases should be a fundamental skill acquired during one's training. Surely it is never too early to acquire this skill when embarking on a career in psychiatry. We all recognise that examinations provide a major (for some essential) incentive to learn. Therefore, unlike Narula (Psychiatric Bulletin, February 2005, 29, 72-73), rather than review the long case format in the Part II examination, I would advocate the use of both the OSCE and long case formats for both parts of the examination. Obviously, this would lead to some logistical problems but would the College fear being accused of placing too much emphasis on clinical acumen?

MacDara McCauley Senior Registrar, St Davnet's Hospital, County Monaghan

\section{Thiamine treatment of Wernicke-Korsakoff syndrome in alcoholism}

I was delighted to read the article by Mclntosh et al (Psychiatric Bulletin, March 2005, 29, 94-97) encouraging the use of parenteral thiamine for the early treatment of Wernicke-Korsakoff syndrome in alcoholism. Such treatment greatly improves outcome in some alcoholics (Guthrie \& Elliott, 1980; Macdonald, 1994).

However the British National Formulary recommends one pair of high-potency ampoules twice daily for 7 days, so the guidelines given fall short of an adequate dose. Also, it is hard to detect any useful clinical response within 2 days; my own experience is that 3-4 weeks are required before improvement in memory function can be detected.

GUTHRIE, A. \& ELLIOTT, W. A. (1980) The nature and reversibility of cerebral impairment in alcoholism: treatment implications. Journal of Studies on Alcohol, 41, 147-155.

MACDONALD, A. J. (1994) A paper that changed my practice: reversible mental impairment in alcoholics. BMJ, 308, 1678

Alasdair Macdonald Consultant Psychiatrist, North Dorset Primary CareTrust, Forston Clinic, Dorchester DT2 9TB

\section{Neuroimaging in dementia}

We agree with Dr Fielding that neuroimaging in dementia is controversial (Psychiatric Bulletin, January 2005, 29, 21-23). Guidelines vary between the relatively restrictive Royal College of Psychiatrists (1995) statement, referred to by Fielding, to the all-inclusive consensus statement from the American Academy of Neurology (2001) in which computed tomography/magnetic resonance imaging (CT/MRI) is recommended.

We conducted a small audit which has some similar findings to those of Fielding Out of 32 patients scanned in the past year whose notes were readily accessible, 25 (79\%) were referred for CT scan according to College guidelines. Only 1 $(3 \%)$ potentially reversible cause of dementia was found: an incidental meningioma which was not treated. This rate compares closely with Fielding's report. We also found a very high prevalence of cerebrovascular disease: ischaemic changes or infarcts being found in 27 patients (85\%). This prevalence is much higher than in Fielding's report, perhaps reflecting variation in radiological reporting and/or geographical variation in the prevalence of this disorder.

The very low incidence of potentially reversible causes may reflect the patient group presenting to old age psychiatry. This may be higher in neurology clinics and other settings. The high prevalence of cerebrovascular disease is perhaps of much greater clinical significance to the old age psychiatrist. There may be treatment implications arising from an emerging view that vascular and Alzheimer pathology co-exist (Langa et al, 2004), and this might be justification for CT as a routine test, as advocated by the draft Scottish Intercollegiate Guideline Network (SIGN)

KNOPMAN, D. S., DEKOSKY, S.T., CUMMINGS, J. L., et al (2001) Practice parameter: Diagnosis of dementia (an evidence-based review). Report of the Quality Standard Sub-Committee of the American Academy of Neurology. Neurology, 56, 1143-1153.

LANGA, K. M., FOSTER, N. L. \& LARSON, E. B. (2004) Mixed dementia. Emerging concepts and therapeutic implications. Journal of the American Medical Association, 292, 2901-2908.

ROYAL COLLEGE OFPSYCHIATRISTS (1995) Consensus Statement on the Assessment of an Elderly Person with Suspected Cognitive Impairment by a Specialist Old Age Psychiatry Service (Council Report CR49). London: Royal College of Psychiatrists.

Michael Hughes Final Year Medical Student *Tom MacEwan Consultant Psychiatrist, Old Age Psychiatry Directorate, Konord, Royal Cornhill Hospital, Cornhill Road, Aberdeen AB25 27H 